\title{
Modeling and Digital Simulation of Interline Power Flow Controller System
}

\author{
A. P.Usha Rani and B. S.Rama Reddy
}

\begin{abstract}
The Interline Power Flow Controller (IPFC) is a voltage source converter based Flexible AC Transmission System (FACTS) controller for series compensation with the unique capability of power flow management among the multiline transmission systems of a substation. The reactive voltage injected by individual Voltage Source Converter (VSC) can be controlled to regulate active power flow in the respective line. While one VSC regulates the DC voltage, the other one controls the reactive power flows in the lines by injecting series active voltage. In this paper, a circuit model for IPFC is developed and simulation of interline power flow controller is done using the proposed circuit model. Simulation is done using MATLAB simulink and PSPICE. The results obtained by MATLAB are compared with the results obtained by PSPICE.
\end{abstract}

Index Terms-Flexible AC Transmission System (FACTS), Interline Power Flow Controller (IPFC), Voltage Source Converter (VSC), Static Synchronous Series Compensator (SSSC).

\section{INTRODUCTION}

The power systems of today are mechanically controlled and as a result there is no high-speed control. Also, such mechanical controls cannot be initiated frequently because mechanical device tend to wear out very quickly compared to static electronic devices. The FACTS technology is essential to alleviate some but not all of these difficulties by enabling utilities to get the most service from their transmission facilities and enhance grid reliability. The possibility that current through a line can be controlled at a reasonable cost enables a large potential of increasing the capacity of existing lines with larger conductors, and use of one of the FACTS controllers to enable corresponding power to flow through such lines under normal and contingency conditions. FACTS controllers can enable a line to carry power closer to its thermal rating. Interline Power Flow Controller (IPFC) is an extension of static synchronous series compensator (SSSC). A mathematical model of the IPFC in steady state operation has been developed in [1]. In [2], the basic principle of the IPFC is discussed in detail and simulation results are shown to demonstrate the capability of the IPFC to realize power balance between transmission systems with two identical parallel lines. The basic characteristics of the IPFC are discussed and two basic control systems for the IPFC are

F.A. Department of Electrical and Electronics Engineering, Jerusalem College of Engineering, Centre for collaborative research with Anna University, Chennai, India. (e-mail: pusharani71@yahoo.com)

S.B. Department of Electrical and Electronics Engineering, Jerusalem College of Engineering, Centre for collaborative research with Anna University, Chennai, India. (e-mail: srr_victory@yahoo.com) proposed to realize the power flow control in [3].

Flexible AC Transmission System (FACTS) controllers such as thyristor-based controllers are described in [4]. IPFC employs a number of VSCs linked at the same DC terminal, each of which can provide series compensation for its own line. In this way, the power optimization of the overall system can be realized in the form of appropriate power transfer through the common DC link from overloaded lines to under-loaded lines [2] - [4]. The performance of a Generalized Interline Power Flow Controller (GIPFC) controlling two balanced independent AC systems is analyzed and evaluated in [5]. Literature [6] describes a combination of fuzzy scheme and Radial Basis Function Neural Network adopted for nonlinear control of Thyristor Controlled Series Capacitor (TCSC) and IPFC. The power flow control design for IPFC is proposed and transfer functions are analyzed in [7]. Paper [8] proposes a powerful tool applied on 3 machine 9 bus test system with two IPFCs, with one loop and optimal power flow method. Mathematical models of IPFC and Generalized UPFC and their implementation in power flow have been presented in [9]. Paper [10] presents IPFC with 12 pulse three level converters and investigates the sub synchronous resonance characteristics. The circuit model for IPFC is not available in the literature [1] to [10]. An attempt is made in the present work to develop circuit model for four bus system with IPFC.

\section{BASIC PRINCIPLE OF INTERLINE POWER FLOW CONTROLLER}

In its general form the interline power flow controller employs number of DC to AC inverters each providing series compensation for a different line as shown in Fig.1. IPFC is designed as a power flow controller with two or more independently controllable static synchronous series compensators (SSSC) which are solid state voltage source converters injecting an almost sinusoidal voltage at variable magnitude and are linked via a common DC capacitor. SSSC is employed to increase the transferable active power on a given line and to balance the loading of a transmission network.

In addition, active power can be exchanged through these series converters via the common DC link in IPFC. It is noted that the sum of the active powers outputted from VSCs to transmission lines should be zero when the losses of the converter circuits can be ignored. A combination of the series connected VSC can inject a voltage with controllable magnitude and phase angle at the fundamental frequency while DC link voltage can be maintained at a desired level. The common DC link is represented by a bidirectional link for active power exchange between 
voltage sources.

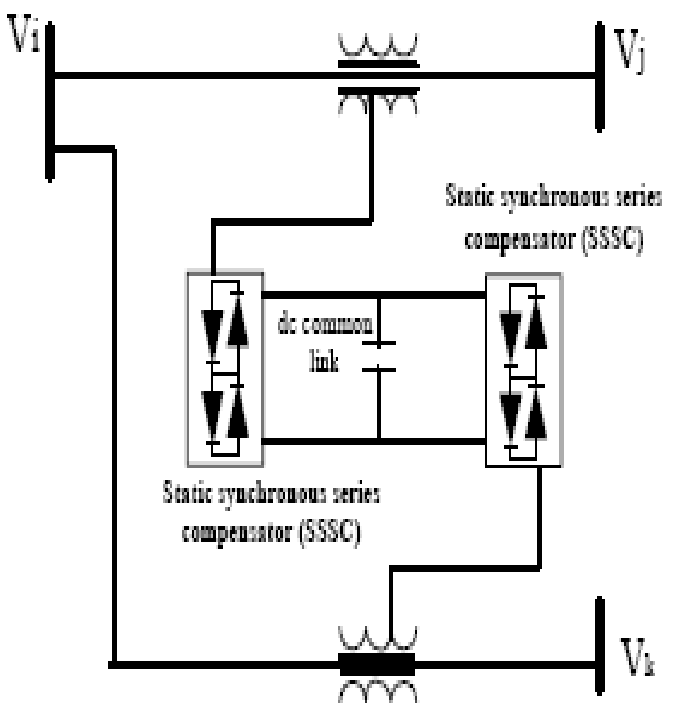

Fig.1. Schematic representation of IPFC

The equivalent circuit of the IPFC is shown in Fig.2.

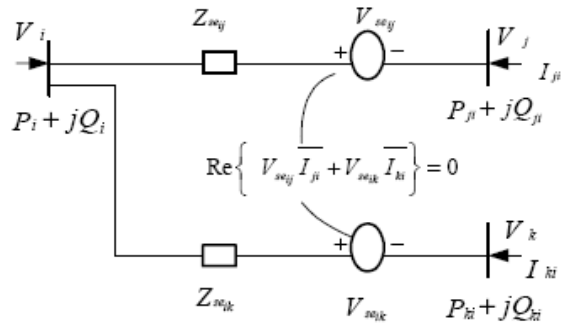

Fig.2. Equivalent circuit of IPFC

The power flow equations are as follows:

$$
\begin{aligned}
P_{i} & =V_{i}^{2} g_{i i}-\sum_{j=1, j \neq i}^{n} V_{i} V_{j}\left(g_{i j} \cos \left(\theta_{j}-\theta_{i}\right)+b_{i j} \sin \left(\theta_{j}-\theta_{i}\right)\right) \\
& -\sum_{j=1, j \neq i}^{n} V_{i} V s e_{i j}\left(g_{i j} \cos \left(\theta_{i}-\theta s e_{i j}\right)+b_{i j} \sin \left(\theta_{i}-\theta s e_{i j}\right)\right) \\
Q_{i} & =V_{i}^{2} b_{i i}-\sum_{j=1, j \neq i}^{n} V_{i} V_{j}\left(g_{i j} \sin \left(\theta_{j}-\theta_{i}\right)+b_{i j} \sin \left(\theta_{j}-\theta_{i}\right)\right) \\
& -\sum_{j=1, j \neq i}^{n} V_{i} V s e_{i j}\left(g_{i j} \sin \left(\theta_{i}-\theta s e_{i j}\right)+b_{i j} \sin \left(\theta_{i}-\theta s e_{i j}\right)\right)
\end{aligned}
$$

$$
\text { where } \begin{array}{ll}
\mathrm{V} & \text { : bus voltage magnitude } \\
\theta & \text { : bus angle } \\
\mathrm{V}_{\mathrm{se}} & \text { : magnitude of injected voltage } \\
\theta_{\mathrm{se}} & \text { : angle of injected voltage }
\end{array}
$$

\section{MATLAB SIMULATION}

Digital Simulation of IPFC system is done using MATLAB simulink and the results are presented.

\section{A. model for ipfc system}

The single phase model of four bus system with IPFC is shown in Fig.3. The transformer between the lines is represented by a dependent voltage source. By providing converters between two transmission lines, the reactive power can be transferred from under loaded line to the over loaded line.

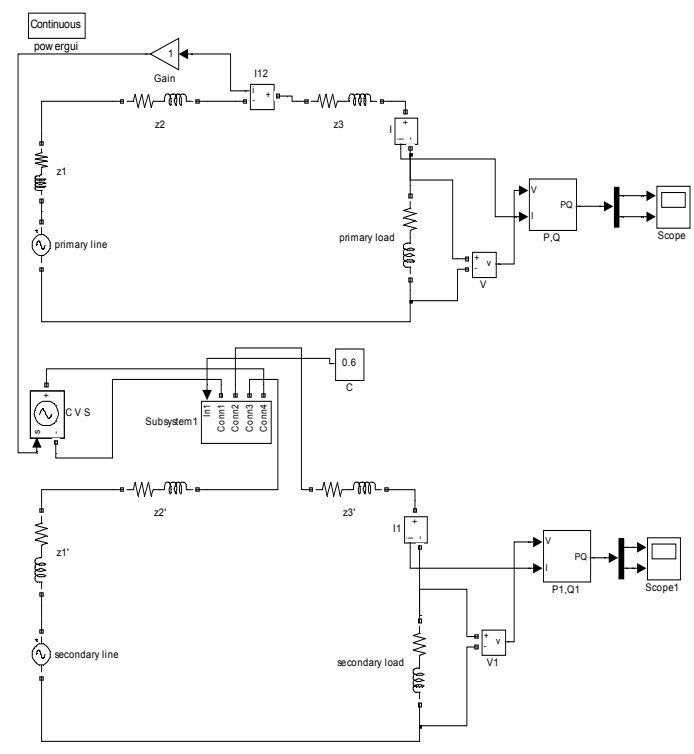

Fig.3. Matlab Circuit model of IPFC system

Rectifier-Inverter subsystem used in the IPFC model is shown in Fig.4. Scopes are connected to measure the real and reactive powers in the loads.

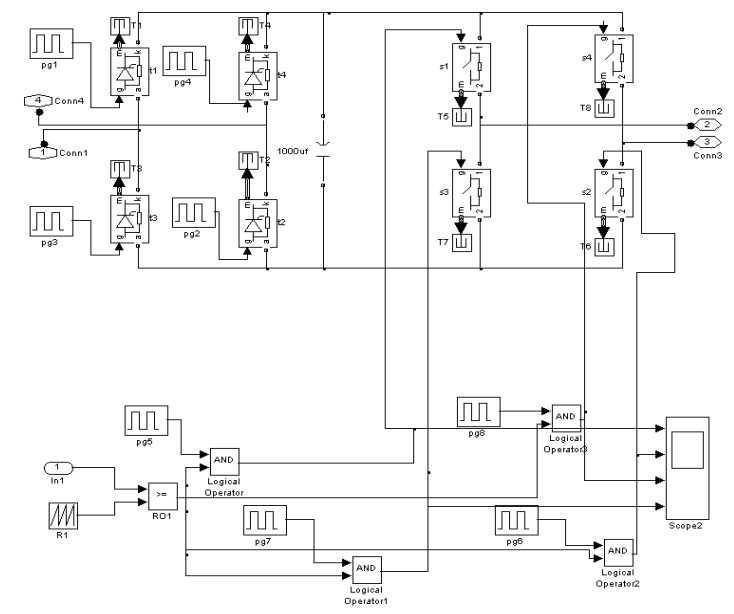

Fig.4. Rectifier-Inverter subsystem

A reference signal is compared with a ramp signal and its output is given as pulse to the switches of the converter. The reactive power of secondary load is 7.094MVAR with primary line operating at $120 \mathrm{kV}$ and the secondary line at $110 \mathrm{kV}$. The plot of reactive power with unequal voltages is shown in Fig.5.

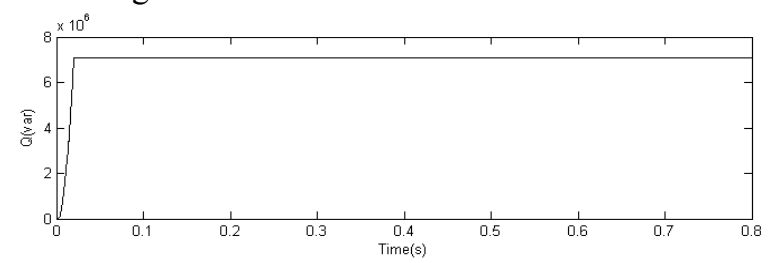

Fig.5. Reactive power of secondary load with unequal voltages 
The reactive power of secondary load is 7.0955MVAR when both lines are operating at $110 \mathrm{kV}$. The plot of reactive power with equal voltages is shown in Fig.6.

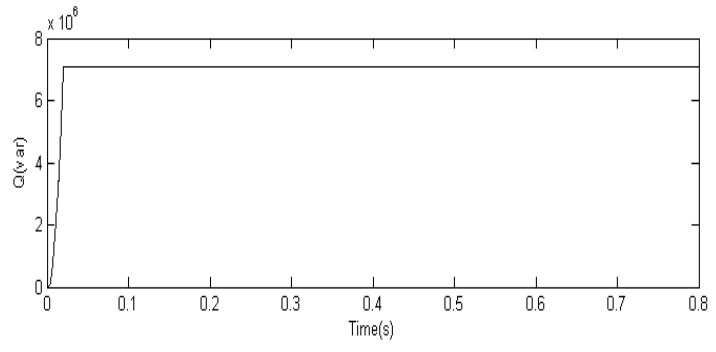

Fig.6. Reactive power of secondary load with equal voltages

Simulation was done with equal voltages on the input sides and different phase angles [Primary input source voltage with phase angle $15^{\circ}$ and secondary source voltage with $30^{\circ}$ ]. Due to the difference in phase angle, there is an increase in the real power of the secondary load when compared to the primary load. The real powers in primary and secondary loads are $8.8 \mathrm{MW}$ and $9.47 \mathrm{MW}$ respectively as shown in Fig.7.
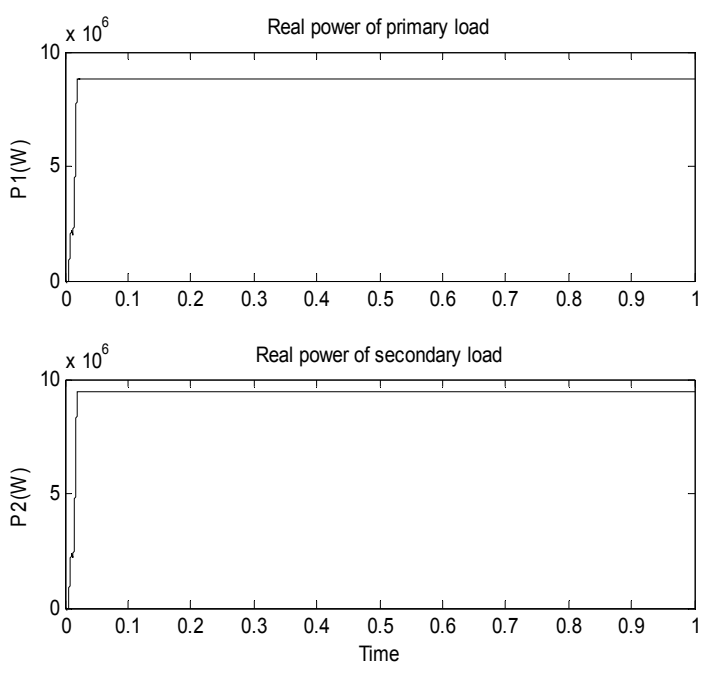

Fig.7. Real power of primary load and secondary load B. Model of closed loop ipfc SYSTEM

The Matlab circuit model of closed loop IPFC system with primary and the secondary loads is shown in Fig.8. Load voltage is sensed and it is rectified. It is compared with a reference signal. The output of pulse generator is used to drive the switches of the inverter. Subsystem 2 senses the voltage across secondary load. Subsystem 3 senses the voltage across primary load. Subsystem 4 represents the pulse generation module.

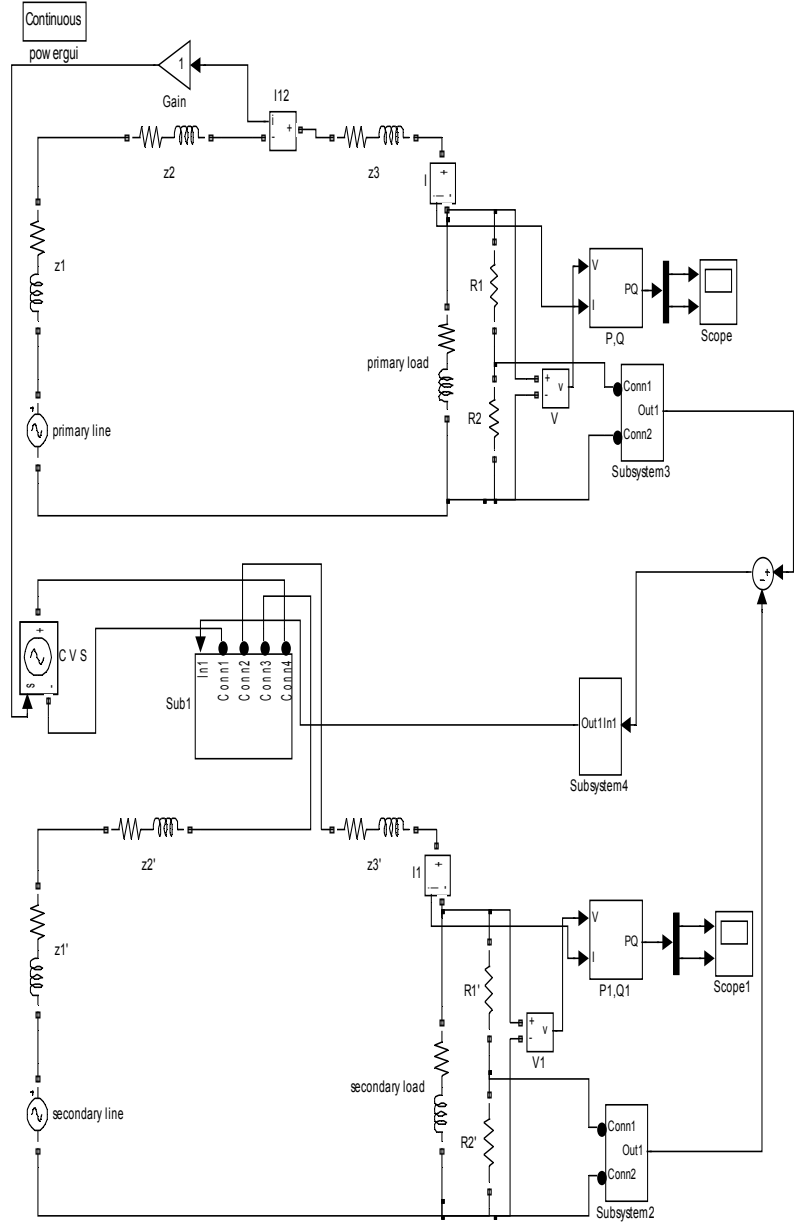

Fig.8. Circuit model of Closed loop IPFC system

With unequal voltages on the input sides ie. primary line input of $120 \mathrm{kV}$ and the secondary line input of $110 \mathrm{kV}$, the reactive power of secondary load is $7.108 \mathrm{MVAR}$ as shown in Fig.9. The reactive power is increased from 7.094MVAR in open loop to 7.108MVAR in closed loop system.

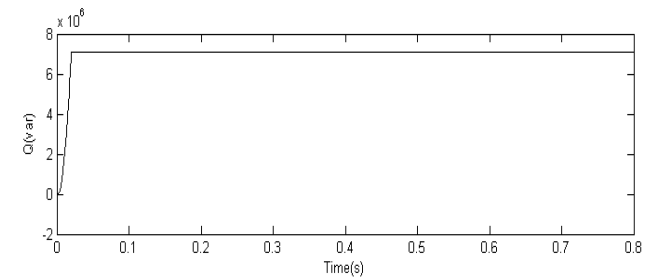

Fig.9. Reactive power of secondary load with unequal voltages

The reactive power of secondary load is 7.109MVAR when both lines are operating at $110 \mathrm{kV}$. as shown in Fig. 10 . The reactive power is increased from 7.0955MVAR in open loop to 7.109MVAR in closed loop system.

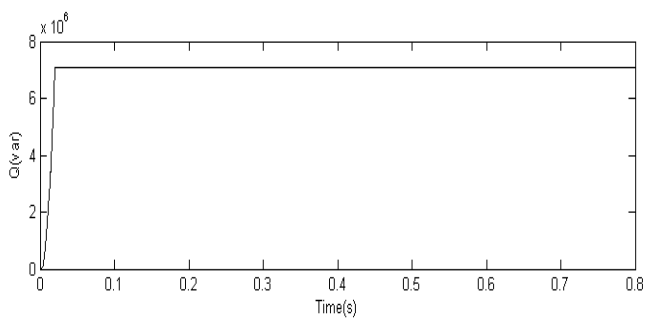

Fig.10. Reactive power of secondary load with equal voltages 
The simulation results of reactive power of secondary load are given in Table. I.

TABLE. I. REACTIVE POWER OF SECONDARY LOAD

\begin{tabular}{|c|c|c|c|}
\hline \multirow{2}{*}{$\begin{array}{c}\text { Primary line } \\
\text { voltage } \\
(\mathrm{kV})\end{array}$} & $\begin{array}{c}\text { Secondary line } \\
\text { voltage }(\mathrm{kV})\end{array}$ & \multicolumn{2}{|c|}{$\begin{array}{c}\text { Reactive power of secondary } \\
\text { load (MVAR) }\end{array}$} \\
\cline { 3 - 4 } & 110 & Open loop & Closed loop \\
\hline 110 & 110 & 7.0955 & 7.109 \\
\hline 120 & & 7.094 & 7.108 \\
& & & \\
\hline
\end{tabular}

The real power of primary load is $8.8 \mathrm{MW}$ and the secondary load is $9.51 \mathrm{MW}$ with primary line operating at $110 \angle 15^{\circ} \mathrm{kV}$ and secondary line operating at $110 \angle 30^{\circ}$ $\mathrm{kV}$ as shown in Fig.11. Thus, in closed loop system, the real power of secondary load increases to $9.51 \mathrm{MW}$ from 9.47MW in open loop system. This is possible by providing converters between two transmission lines. By controlling the phase angle of the input voltages, the flow of real power between lines having equal input voltages can be controlled.
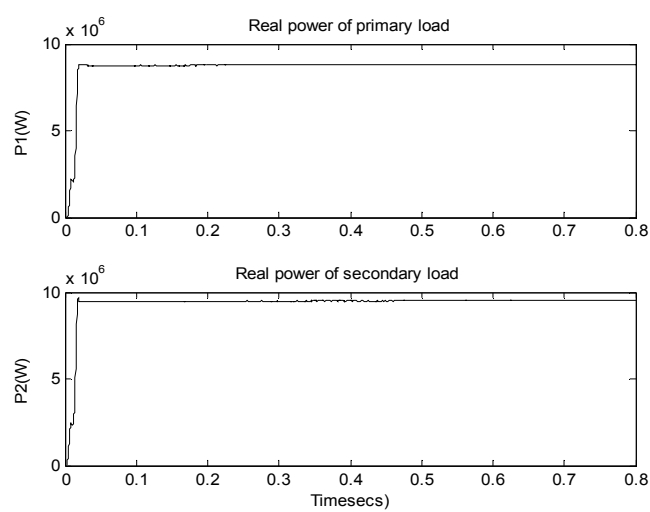

Fig.11. Real power of primary load and secondary load

The simulation results of real power in primary load and secondary load are given in Table. II.

\begin{tabular}{|} 
TABLE. II. REAL POWER OF PRIMARY AND SECONDARY LOADS \\
\begin{tabular}{|c|c|c|}
\hline \multirow{2}{*}{$\begin{array}{c}\text { Type of } \\
\text { system }\end{array}$} & \multicolumn{2}{|c|}{ Real power (MW) } \\
\cline { 2 - 3 } & Primary load & $\begin{array}{c}\text { Secondary } \\
\text { load }\end{array}$ \\
\hline Open loop & 8.8 & 9.47 \\
\hline Closed loop & 8.8 & 9.51 \\
\hline
\end{tabular}
\end{tabular}

There is an increase in the real power of secondary load due to the closed loop operation of Interline Power Flow Controller.

\section{PSPICE SIMULATION}

The IPFC system is also simulated using PSPICE and the details are presented here. IPFC system is modeled using the elements of PSPICE.

\section{A. Model of IPFC system}

The Pspice model of IPFC system is shown in Fig.12. Series transformers are represented as voltage dependent sources. Line impedance is divided into two parts as shown.

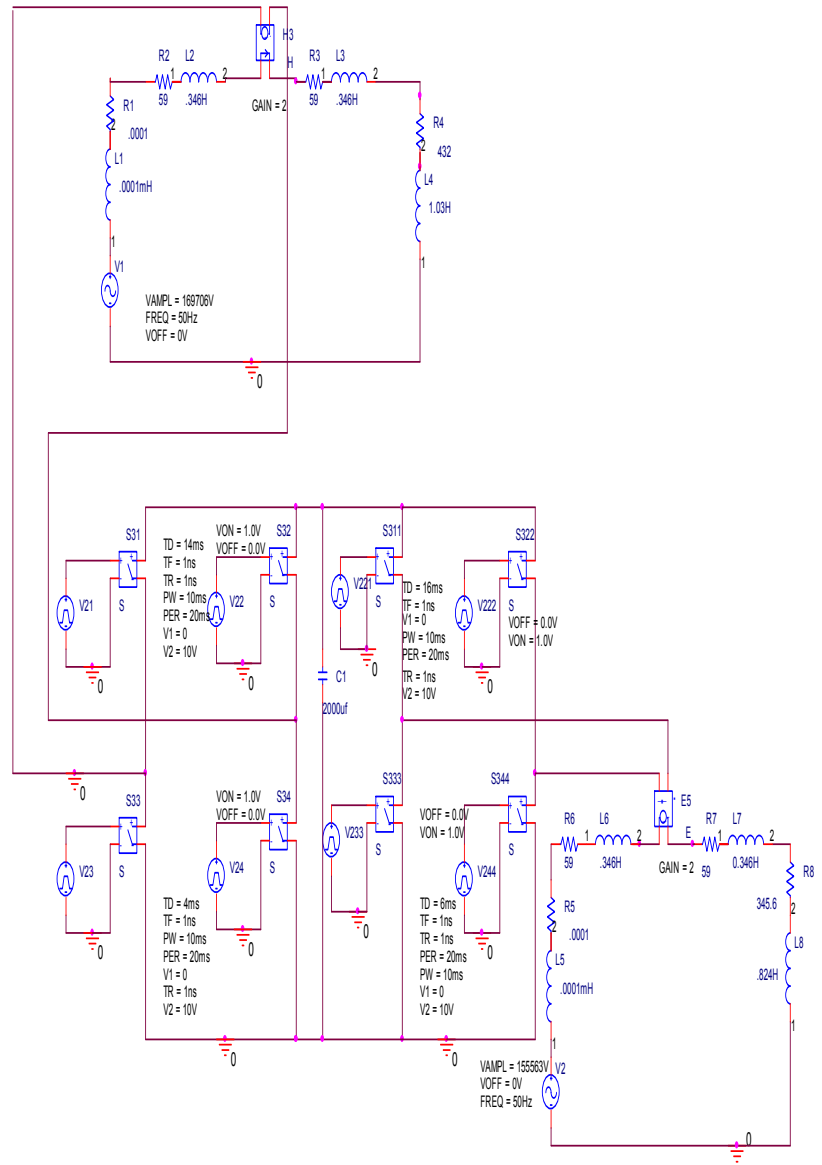

Fig.12. PSPICE Circuit model of IPFC system

With unequal voltages on the input sides ie. primary line input of $120 \mathrm{kV}$ and the secondary line input of $110 \mathrm{kV}$, the reactive power in secondary load is 7.07MVAR as shown in Fig.13.

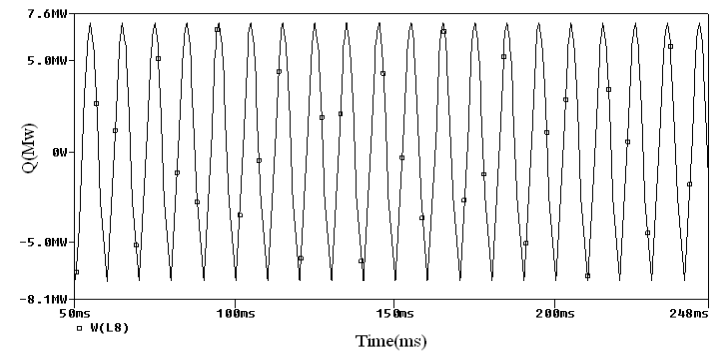

Fig.13. Reactive power of secondary load with unequal voltages

The reactive power in secondary load is 7.072MVAR with equal voltages on primary line and secondary line operating at $110 \mathrm{kV}$ as shown in Fig. 14.

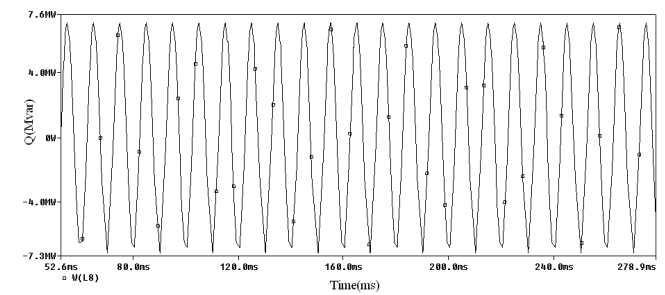

Fig.14. Reactive power of secondary load with equal voltages 
Simulation is done with equal voltages on the input sides and different phase angles [Primary line operating at $110 \mathrm{kV}$ with phase angle $15^{\circ}$ and secondary line operating at $110 \mathrm{kV}$ with phase angle $30^{\circ}$ ]. There is an increase in the real power of the secondary load. The real powers in primary and secondary loads are $8.8 \mathrm{MW}$ and $9.42 \mathrm{MW}$ respectively. The real power output of secondary load is $9.42 \mathrm{MW}$ as shown in Fig. 15.

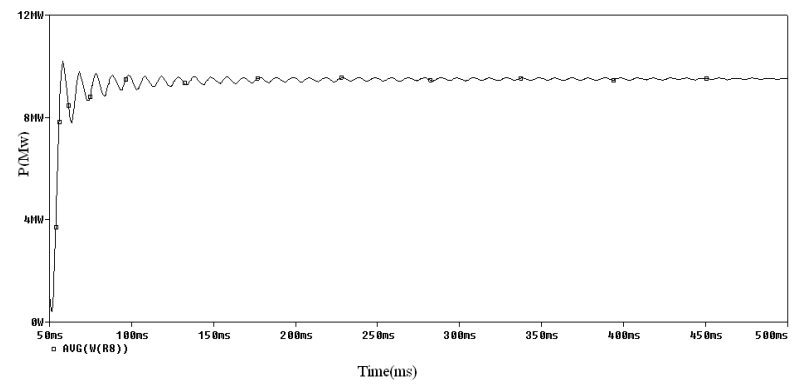

Fig.15. Real power of secondary load

\section{B. Model of Closed loop System Using Pspice}

The PSPICE based closed loop controlled IPFC circuit for reactive power compensation is shown in Fig.16. The converter can function as a phase controlled rectifier or inverter. AC output of primary and secondary lines is rectified and attenuated. The outputs of attenuator are given to the comparator. The difference in input voltages makes the comparator output high and the switch gets closed. This allows power exchange between the transmission lines through the $\mathrm{AC}$ to $\mathrm{AC}$ converter system.

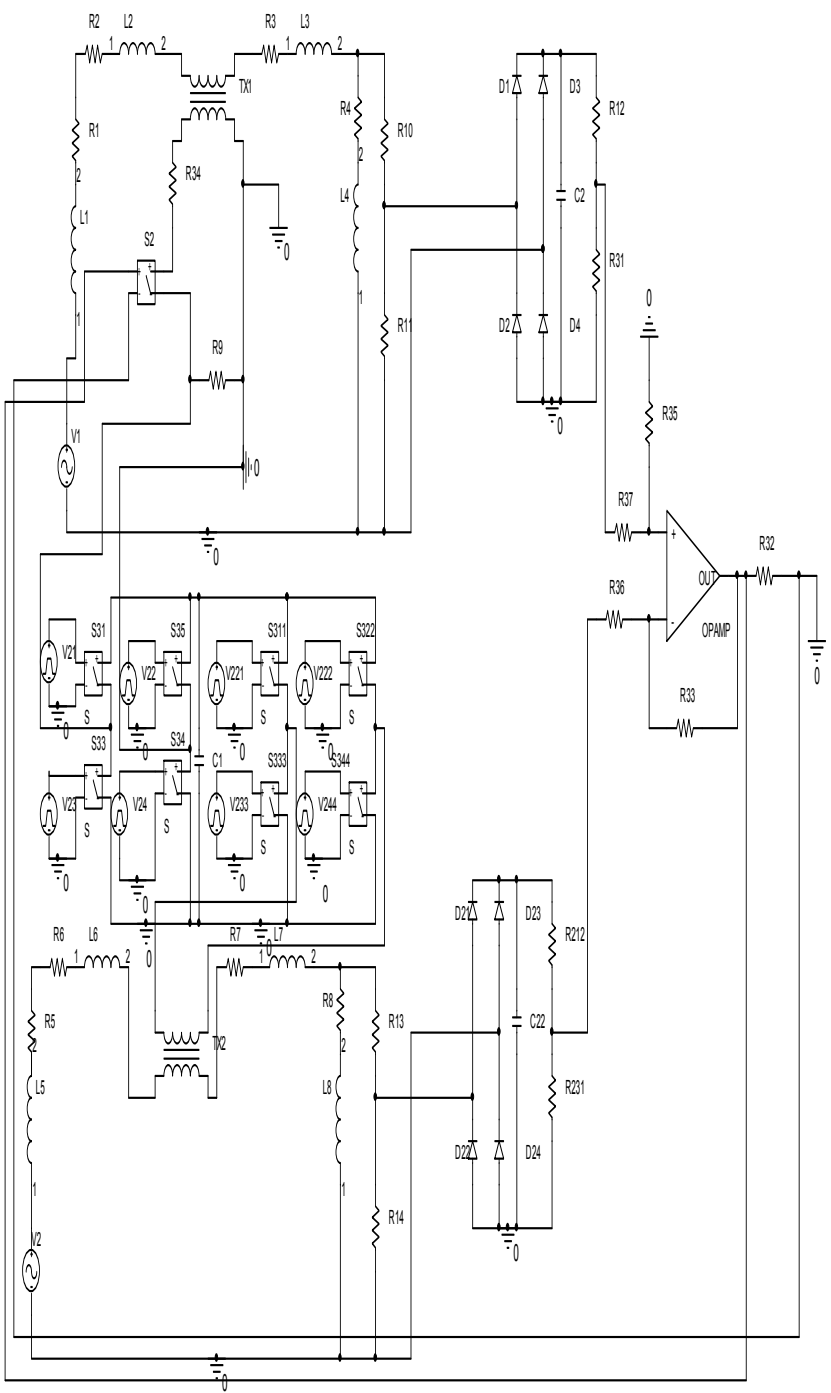

Fig.16. closed loop controlled IPFC system using pspice

The reactive power in secondary load is $7.073 \mathrm{MVAR}$ with unequal voltages on the input sides ie. primary line operating at $120 \mathrm{kV}$ and the secondary line operating at $110 \mathrm{kV}$ as shown in Fig.17. The reactive power increases from 7.07MVAR in open loop to 7.073MVAR in closed loop system.

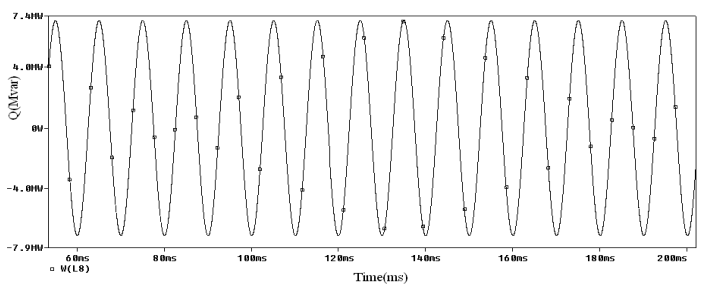

Fig.17. Reactive power of secondary load with unequal voltages

With equal voltages on the input sides ie. primary line and secondary line inputs are $110 \mathrm{kV}$, the reactive power in secondary load is 7.0728MVAR as shown in Fig.18.

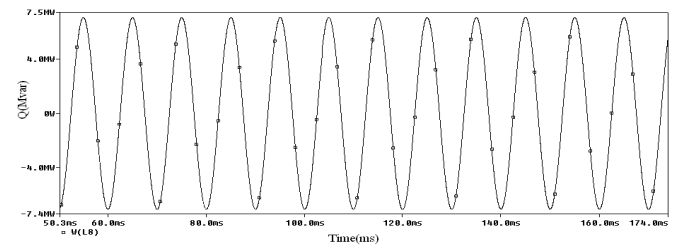

Fig.18. Reactive power of secondary load with equal voltages 
The simulation results of reactive power in secondary load are given in Table III.

TABLE. III. REACTIVE POWER IN SECONDARY LOAD USING PSPICE

\begin{tabular}{|c|c|c|c|}
\hline \multirow{2}{*}{$\begin{array}{c}\text { Primary line } \\
\text { voltage } \\
(\mathrm{kV})\end{array}$} & \multirow[t]{2}{*}{$\begin{array}{c}\text { Secondary line } \\
\text { voltage }(\mathrm{kV})\end{array}$} & \multicolumn{2}{|c|}{$\begin{array}{c}\text { Reactive power in } \\
\text { secondary load (MVAR) }\end{array}$} \\
\hline & & Open loop & Closed loop \\
\hline 110 & 110 & 7.072 & 7.0728 \\
\hline 120 & 110 & 7.07 & 7.073 \\
\hline
\end{tabular}

The real power of primary load is $8.8 \mathrm{MW}$ and the secondary load is $9.47 \mathrm{MW}$ with primary line operating at $110 \angle 15^{\circ} \mathrm{kV}$ and secondary line operating at $110 \angle 30^{\circ} \mathrm{kV}$ as shown in Fig.19. Thus, in closed loop system, the real power of secondary load increases to $9.47 \mathrm{MW}$ from 9.42MW in open loop system. This is possible by providing converters between two transmission lines. By controlling the phase angle of the injected voltage, the flow of real power between lines having equal input voltages can be controlled.

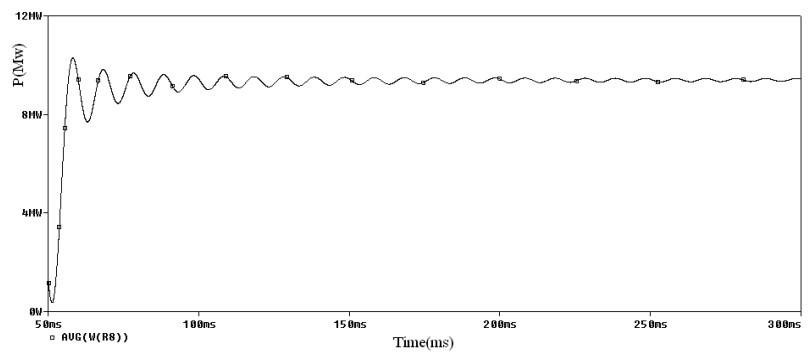

Fig.19.Real power of secondary load

The simulation results of real power in primary load and secondary load are given in Table. IV.

TABLE. IV. REAL POWER OF PRIMARY LOAD AND SECONDARY LOAD USING PSPICE

\begin{tabular}{|c|c|c|}
\hline Type of system & \multicolumn{2}{|c|}{ Real power (MW) } \\
\cline { 2 - 3 } & Primary load & Secondary load \\
\hline Open loop & 8.8 & 9.42 \\
\hline Closed loop & 8.8 & 9.47 \\
\hline
\end{tabular}

\section{CONCLUSION}

IPFC is capable of balancing the power through the lines. The power quality is improved since IPFC permits additional power. The circuit models for IPFC system are developed using matlab and pspice. These models are used for simulating a four bus system. The simulation results using matlab and PSPICE are presented. The simulation results of Matlab closely agree with the results of Pspice system. IPFC increases the real power transfer and improves the voltage profile.

\section{REFERENCES}

[1] K. R. Padiyar , Nagesh Prabhu, "Analysis of SSR With Three-Level Twelve-Pulse VSC-Based Interline Power-Flow Controller", IEEE Transactions on Power Delivery, vol 22, No 3, July 2007.
[2] Yankui Zhang, Yan Zhang, and Chen Chen, "A Novel Power Injection Model of IPFC for Power Flow Analysis Inclusive of Practical Constraints", IEEE Transactions on Power Systems, Vol 21, No 4, November 2006, pp. 1550-1556.

[3] Jianhong Chen, Tjing T.Lie, D.M. Vilathgamuwa, "Basic Control of Interline Power Flow Controller", IEEE 2002, pp. 521-525.

[4] R.L. Vasquez Arnez, L. Cera Zanetta Jr., "Steady state Multi-Line Power Flow through the Generalized IPFC ", IEEE/PES Transmission \& Distribution conference, 2004, pp. 28-33.

[5] A.Kazemi, E.Karimi, "The Effect of Interline Power Flow Controller (IPFC) on Demanding Inter-area Oscillations in the Interconnected Power systems", IEEE ISIE 2006, July 9-12, 2006, Montreal, Quebec, Canada.

[6] S.Teerathana, A. Yokoyama, Y. Nakachi, M. Yasumatsu, "An Optimal Power Flow Control Method of Power System by Interline Power Flow Controller ", IEEE 2004, pp. 343-346.

[7] R. Leon Vasquez-Arnez, Lulz Cera Zanetta, "A Novel Approach for Modeling the Steady-State VSC-Based Multiline FACTS Controllers and Their Operational Constraints", IEEE Transactions on Power Delivery, 2007, pp. 1-8.

[8] Jun Zhang, Akihiko Yokoyama, "Optimal Power Flow Control for Congestion Management by Interline Power Flow Controller (IPFC)", International Conference on Power System Technology, 2006, pp. 16.

[9] V. Diez-Valencia, U.D. Annakage, D. Jacobson, "Interline Power Flow Controller (IPFC) Steady State Operation", IEEE Canadian Conference on Electrical \& Computer Engineering, 2002, pp. 280284.

[10] Power Engineers Handbook by Tamil Nadu Electricity Board Engineering Association, Sixth edition, 2002.

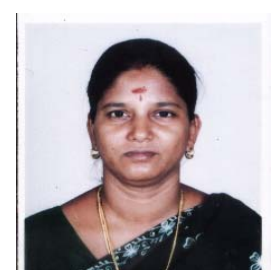

First A. P. Usha Rani is an Associate Professor in Electrical and Electronics Engineering Department, Jerusalem College of Engineering, Chennai, India. She received her B.E. degree in Electrical \& Electronics Engineering from the Government College of Technology, Coimbatore, India in 1991, M.E. degree in Power Systems from College of Engineering, Anna University, Chennai, India in 2001. Her earlier industrial experience was with Chemin Controls, Pondicherry, India. She has 13 years of teaching experience. Her research interests include FACTS and application of power electronics to power quality problems.

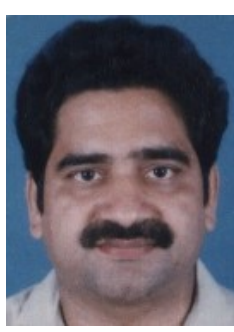

Second B. S. Rama Reddy is Professor and Dean of Electrical \& Electronics Engineering Department, Jerusalem College of Engineering, Chennai, India. He obtained his D.E.E. from S.M.V.M. polytechnic, Tanuku, A.P., A.M.I.E. in Electrical Engineering from Institution of Engineers (India), M.E. in Power Systems from Anna University, Chennai and Ph.D in the area of Power Electronics from Anna University, Chennai, India. He has published over 20 technical papers in national and international conferences proceedings / journals. He has secured A.M.I.E. institution gold medal for obtaining highest marks. He has secured AIMO best project award and Vijaya Ratna Award. He has worked in Tata Consulting Engineers, Bangalore and Anna University, Chennai. He has 18 years of teaching experience. His research interests include the areas of resonant converters and FACTS. He is life member of Institution of Engineers (India), Indian Society for Technical Education, Systems Society of India, Society of Power Engineers and Institution of Electronics and Telecommunication Engineers (India). He has published text books on Power Electronics, Solid State Circuits and Electronic circuits. 